\title{
A Decorporealized Theory? Considerations About Luhmann's Conception of the Body
}

http://dx.doi.org/10.1590/1982-88371826104125

\author{
Santiago Gabriel Calise ${ }^{1}$
}

\begin{abstract}
The aim of this paper is to analyze the concept of body developed by Luhmann's systems theory. Privileged places where one can look for the body will be the interpenetration between human beings and the concept of socialization. Another fundamental problem is the relationship between semantics and body, although the most explicit presence of the body in this theory comes with the concept of symbiotic mechanisms or symbols. The last place where this enquiry will look for a bodily reference are emotions, which were highly ignored by Luhmann. Alternative approaches explored in the paper are treating the body as a structure, as a medium or as an internal environment.
\end{abstract}

Keywords: interpenetration; symbiotic mechanisms; emotions; semantics, Luhmann

Resumen: El objetivo de este trabajo es analizar el concepto de cuerpo desarrollado por la teoría de sistemas de Luhmann. Algunos lugares privilegiados para encontrar al cuerpo en este contexto son la interpenetración entre seres humanos y el concepto de socialización. Otro problema fundamental es la relación entre semántica y cuerpo, si bien la presencia más explícita del cuerpo en esta teoría se encuentra en el concepto de mecanismos o símbolos simbióticos. El último lugar donde esta investigación buscará una referencia corporal es en las emociones, las cuales fueron largamente ignoradas por Luhmann. También se explorarán abordajes alternativos como tratar al cuerpo como estructura, como medio o como entorno interno.

Palabras clave: interpenetración; mecanismos simbióticos; emociones; semántica, Luhmann

The aim of this paper is the analysis of the concept of "body" developed by Luhmann's systems theory. In the last decades, the treatment devoted to the body by sociology and other near disciplines has thrived conspicuously, by the influence of multiple factors, which cannot be analyzed in this article ${ }^{2}$. In this study, the point of departure will be the "Cartesian" conception of the body, so as to observe to which extent this theory can

\footnotetext{
${ }^{1}$ Universidad de Buenos Aires, Faculdad de Ciencias Sociales, Instituto de Investigaciones Gino Germani (IIGG), Pte J. E. Uriburu 950, 6to, C1114AAD, Ciudad Autonoma de Buenos Aires, Argentina. Email: c_santiago_g2000@yahoo.com.ar

${ }^{2}$ For that purpose it is recommended to revise TURNER 1991.
} 


\section{Calise, S. G. - Luhmann's Conception of the Body}

differentiate itself from the philosophical tradition, which until today exercises a strong ascendant. This will be useful to start to differentiate between the organism and the body, and state if the body can assume the category of system, as this theory interprets it. With the introduction of the delineation of several systems, the path to the analysis of the relationship between them will be smoothed, with the concept of interpenetration. It is in a particular sort of interpenetration, namely that between social system and the human being - which gave rise to the sphere of intimacy - where the most fundamental and general theses underlie, which this theory installs in order to understand the relationship between the body and the rest of the systems. Naturally, this work is not free from interpretations and ambiguities, as it is the question about the theoretical status attributable to the body. This core indeterminacy will launch many unanswered questions, for which there are no unequivocal answers.

Other privileged places where one can look for the body are the feelings and emotions, and, in the context of the generalized symbolic media of communication, the symbiotic mechanisms. Lastly, as a conclusion, the departure point - the dualism between body and mind - will be picked up, so as to observe the possible criticism this posture implies.

\section{The official doctrine and systems theory}

According to HAHN and JАCOB (1993), the luhmannian conception of the body or the body-mind relationship (or consciousness or psychic system, more appropriately for systems theory) entails no break up with the European thought tradition, emblematically headed by Descartes. In this sense, Luhmann reproduces, in other terms, the classic dualism between res cogitans and res extensa, now recycled under the systemic vocabulary. As it will be explained below without an apologetic spirit, but, on the contrary, avoiding polemics which tend to simplify the theoretical "adversaries", it will be shown how, even if Luhmann continues to defend a clear differentiation between the psychic and the organic, it is unfair to maintain that his theory repurposes what, ironically, RYLE (2009) named the "official doctrine".

As this conception states, each human being has a body and a mind. On the one hand, bodies are provided of spatiality and, owing to this condition, they are subjected to the laws of mechanics, which govern all the bodies that inhabit the space. As a 


\section{Calise, S. G. - Luhmann's Conception of the Body}

consequence, processes and corporal states of the human being, as those of the rest of the bodies, will be examinable by external observers. On the contrary, minds do not inhabit space, and, therefore, they will not be submitted to the laws of mechanics. Moreover, in parallel opposition to bodies, mental processes will not be observable for external subjects, and for that reason only, each mind could recognize their own states and processes. Then, concludes Ryle, even if the human body is conceived as an engine, this engine or this machine is not comparable to any non-human engine or machine, as this would be governed by another internal engine. This conception is named by the English philosopher, with a pretty metaphor (or a sarcasm), "the dogma of the ghost in the machine".

A first observation that must be made is that systems theory, in contrast to the Cartesian conception of the world, which divides it into extension and thought, departs from the presupposition that there are systems ${ }^{3}$, and there are four types of them: organisms, psychic systems, social systems and machines. Each of these systems has the characteristic of performing only one operation: in the case of organic systems this will be life; in the psychic systems, attention ${ }^{4}$; and communication for social systems. In this context, it is imaginable that the body could be a sort of organic system; consequently, this theory would reintroduce, in a modern fashion and with more complex concepts, something similar to the outlines of Descartes. This notwithstanding, for systems theory, body is not a system, but, it would be a conglomerate of living systems, so the organism would be a symbiosis of numerous autopoietic systems with a general genetic program (1995d) ${ }^{5}$. Body will not be a system, as it would not perform any particular operation; on the contrary, there would be the different organic systems responsible for the performance of different types of operation, which allows the prosecution of the autopoiesis of life.

It must also be emphasized that the biological is not considered, in this theory, as a mere machine subdued to the laws of the Newtonian mechanics. As a consequence, in this context, Luhmann introduces the vON FOERSTER's (2003) distinction between trivial and non-trivial machines. The first ones are characterized by associating, in a

\footnotetext{
${ }^{3}$ It must be stressed that systems, for Luhmann, exist; namely, they are not mere analytic constructions as Parsons proposed.

${ }^{4}$ The operation of psychic systems is a very complex problem, to which Luhmann did not provide a definitive solution. At first, he conceived of thoughts as the operations of the system, but then he admitted not being satisfied with it and he suggested attention (1995a). It is difficult to say to which extent this solution must be considered the definitive one.

5 In order not to repeat Luhmann's surname each time, we will only quote the year of the work.
} 


\section{Calise, S. G. - Luhmann's Conception of the Body}

deterministic way, a certain input with an output. On the contrary, in the case of nontrivial machines, an output is not based on the immediately preceding input, but that output would depend on a sequence of particular inputs, which can go back to a faraway past, just like an output also rooted in a remote past. This concept is bonded to the category of complex system, which encompasses organic, psychic and social systems. Complexity, for Luhmann, emerges as a result of the immanent limitation to the capacity of a system to couple in every moment, each element with each other (1984; 1995c). This means that the system is coerced to select. As the elements or operations, which constitute every system, are temporal events - which, as soon as they appear, disappear - the system, in order to proceed with its autopoiesis, needs to continuously bind operations. Thus, the system must decide constantly, which operation will follow the other, so every selection is contingent, as each of them could have been different.

The aforesaid is useful to show the radical differences that can be found, when one tries to understand the biological side of the body. If for the tradition - which conventionally finds its point of departure in Descartes - the corporeal element, even from the biological point of view, is understood as a mere mechanism, then even the biological is simplified in an excessive way, as it is reduced to pure mechanism, which obeys to the laws of mechanics. Therefore, this can be a first step in getting away from the tradition, "untrivializing" the organic.

\section{Interpenetration(s)}

The concept of interpenetration, as admits the very author, is explicitly taken from the works of Parsons, even if LUHMANN is not completely at ease with it, because of the prefix “inter" (2004). In subsequent publications to Social Systems, where the concept of interpenetration dominates, the German sociologist will introduce in a more frequent way the category of "structural coupling", proceeding from the works of MATURANA and VARELA. In spite of this, in Die Gesellschaft der Gesellschaft (1997), LUHMANN still continues to talk about interpenetration and structural coupling, even though the use of the first one was reduced to the minimum. This means that during the years there is no complete process of substitution, as they are not completely interchangeable, because the difference lies in the fact that interpenetration will be interpreted as a particular case of structural coupling, specifically one in which there is co-evolution. 


\section{Calise, S. G. - Luhmann's Conception of the Body}

The concept of interpenetration, particularly in the case of the relationship between psychic and social systems, designates the situation where the systems enable each other by introducing their own already-constituted complexity into each other. Thus the receiver exercises a retroactive influence on the structures of the penetrator (1995c). Interpenetration is a permanent condition for psychic and social systems, so none of them can "disconnect" themselves from this relationship. What is more, this coupling is so radical, that they emerge in co-evolution; consequently, it would be senseless to ask which of the two preexists or originates the other.

There is another sort of interpenetration, which exists between human beings, defining the last ones as the whole formed by the psychic system and the body. That interpenetration is called intimacy, which "comes into being when more and more domains of personal experience and bodily behavior become accessible and relevant to another human being and vice versa. This is possible only if double contingency is operationalized by personal attribution" (1995c: 224). Anyway, it must be taken into account that intimacy is a phenomenon that, historically, has increased, especially under the effect of functional differentiation. Concurrently, in this modern context of functional differentiation, there is an intensification of the personal individualization. Then, "only when this interest in the I-ness of personality has gained sufficient societal and cultural acceptance can the differentiation of intimate relations occur, in which everyone contributes what is most intimately his own and receives even better returns" (1995c: 225). Thus, it is clear that human interpenetration is only possible, because there is communication, as well as the human being a product of social interpenetration.

These last remarks could cause one to think that interpenetration between human beings has no greater importance, due to the fact that, even the physical contact experiences would be significant as generated by society.

Instead, intimacy includes what is incommunicable and therefore includes the experience of incommunicability. Alter is significant for ego in ways that ego cannot communicate to alter. Ego does not just lack words or the time for communication, nor is it a matter of sparing the other communication with which the other could not cope. Communication itself would give the utterance an unintended meaning, and because within the condition of intimacy one knows or feels this, one does not do it (1995c: 228).

This means that intimacy is an essentially paradoxical space. On the one hand, it is the result of social evolution; hence its meaning is socially generated through 


\section{Calise, S. G. - Luhmann's Conception of the Body}

communication. On the other hand, intimacy hosts the incommunicable and the socially formed experience of incommunicability. If one would like to communicate that experience, it would be necessary to transform it into information, which would turn on one of the three components of communication. As communication always requires an answer, positive or negative, and, because a lack of answer can be interpreted as an answer, in a domain prone to conflict, most of the times it is better to be still. This is a deeply socialized borderland, but, at the same time, it is impossible to describe it communicatively; it is one of the favorite spheres, where the body, beyond the mere organicity, becomes so particularly socially meaningful, that it turns out to be unutterable.

\section{Socialization}

Those premises allow one to take another step and get nearer to the concept of socialization, which is defined as the process through which, by means of interpenetration, the psychic system and the human being's bodily behavior (controlled by the psychic system) is formed. One interpretation of this definition can be that socialization only forms the bodily behavior that the psychic system can control. As a result, all the psychic uncontrolled behavior would not be a product of socialization. In this sense, the body would not be capable of incorporating social meaning beyond what consciousness can observe. If this is accepted, this posture would be in opposition to the results of other theoretical and empirical research, like Pierre BouRDIEU's (1980), who understands that the practical sense represents the social need turned into nature, to wit, converted into motor schemata and bodily automatisms. Bourdieu's viewpoint, much more than Luhmann's, is deeply anchored on MERLEAU-PONTY's (2001) phenomenology, who understands that bodily manifestations are meaningful in themselves, so they are not an accompaniment or repercussion of conscious states. This is due to the fact that the body is intentional in itself, as intentionality precedes intelligence and allows the world to be experienced before being thought.

Another aspect of this concept is that Luhmann states that socialization is always self-socialization, since there is no transmission of a meaning pattern (Sinnmuster) from one system to another, as this is an essentially self-referential process of a system that provokes and experiences socialization. This is a core point for the theory, not only 
because it can imply an emphatic change with respect to traditional theories, which usually utilize the transmission metaphor, but also because here it is argued that only systems can "socialize". This derives from the assumption that socialization is a selfreferential process, which is developed inside a system. The clearer consequence for the topic of this article is, as the body is not a system, this concept of socialization would refer, fundamentally, to psychic systems. The only way to think about a socialization process of the body without the conciousness' intervention, implies the supposition that the diverse organic systems that compose the body - which does not operate in the medium of meaning - could produce some structural changes as a result of their exposition to the social. If one decides to assume that possibility, there are two fundamental difficulties. On the one hand, there is an epistemological obstacle of the very theory, which claims that the contact between social and organic systems is always mediated by the psychic system. As a consequence, to allow a direct contact between organism and society it would be necessary to break the hierarchical order of structural couplings. On the other side, it is of suspected sociological relevance to suppose that society can produce some sort of structural reorganization as a result of socialization ${ }^{6}$. Following BOURDIEU, what is most important for sociology on this topic is the bodily hexis, the given image of the body, the utilization of it. That is why it is of minor importance for sociology to study whether communication can produce any structural change in the digestive system. In this sense, for example, for FOUCAULT in the research contained in Histoire de la sexualité (1976), the possible evolutionary changes in the sexual organs are irrelevant, as his problem lies in the way bodies are disciplined. Although these contributions can be very valuable, they cannot provide a theoretical solution in the level of abstraction that handles systems theory. In this way, the lack of theoretical depth is covered by rhetorical figures and a flowery vocabulary, which can be useful to give a transitory answer, but they signal the need for further research in a theoretical answer.

\footnotetext{
${ }^{6}$ Every effort to think on the operative interference of society within any organic system would end in the destruction of one of the fundamental presuppositions of the theory: operative closure. Anyway, LUHMANN leaves open the possibility that sociocultural evolution could influence organic evolution (1995). Although, the author neither explains nor illustrates this scenario with an example.
} 


\section{The "use of the body"}

Returning to the sociological interest on the body, LUHMANN admits that his concern on this topic lies in "the everyday use of the body in social systems" (1995c: 245). Discussing a paragraph of George Mead, where the American philosopher states that gesture is the mechanism that allows the sequentiality of social order, Luhmann profits to introduce some reflections on the problem. To begin with, gesture does not explain anything, it would only give a name to the result. In the context of double contingency, specification is explained by the double specification; as a consequence, the specification of the potentiality of bodily behavior results from the given use. Thus, the body generates its own reduction of complexity.

Approaching the problem with more specific social contexts, Luhmann claims that, today, corporeality is a general premise of social life. Hence, for this society, the difference corporeality / non-corporeality became socially irrelevant, as every human being presupposes to be the "inhabitant" of a body. In this also highly abstract sense, corporeality finds social relevancy as far as it becomes condition, opportunity and resource for the differentiation of social systems, at the same time that it can be a decisive premise for the bond operations of these systems.

Making a brief historical analysis, Luhmann states that, throughout the civilization process - citing explicitly Norbert Elias - the body was reinforced and refined, as potential for gesture. The analysis of literary and scientific texts, especially from the 18th century, makes the author think that the emphasis and the theorization on gesture occupy the place of an absent psychology. On the contrary, the 19th century becomes witness to the expansion of psychology at the expense of rhetoric and gesture, a process which ends with the discovery of the unconscious. According to Luhmann, this has allowed the psychic to emancipate itself from the body / soul schema, resulting in a lack of value of the culture of the body as an indicator of psychic processes. Then, mutual interpenetration in social life oriented by the schema conscious / unconscious allows the inclusion of bodily behaviors as psychically steered.

Regarding the use of the body in specific social contexts in modern society, Luhmann distinguishes three different situations. The first one refers to the possibility of an exact tuning and to a rhythm in the coordination of the behavior over corporeality, which is not possible under control of consciousness. The prototypical example of this 


\section{Calise, S. G. - Luhmann's Conception of the Body}

is dance. On the bases of the aforesaid, it is possible to make two observations. On the one hand, psyche, although Luhmann names the operative mode of psychic systems as "consciousness", could function in a conscious and unconscious way. If this is admitted, it is highly difficult, especially at an empirical level, to try to determine which socially learnt bodily behavior is actually learnt through the unconscious intervention of the psychic system between body and social system, or if it is the body, which directly learns. On the other hand, the coordination of the different bodies, when movements are highly complex and rhythmic, is usually not possible to accomplish, if consciousness controls the process. This opens the possibility to think about a social behavior - as far as socially learnt, but also because it implies the participation of more than a body without the intervention of the psychic system. In this way, it can be concluded that it would be necessary to reformulate the definition of socialization, with the aim of clarifying the problem of the psychic control of the body, or to invent another term to designate the process through which the body learns certain social patterns.

The second situation is sport. With respect to this, Luhmann states that it legitimates the behavior of its own body, through the meaning of the body itself, without the need to turn to external meaning spheres. The third social context makes reference to the symbiotic mechanisms, which will be analyzed later.

\section{Semantics and body}

Another polemic point corresponds to the relationship between social semantics and body. Here, the author claims that the semantics of the body influence indisputably the bodily feeling and the body usage. At the same time, it is related to the change of forms in the sociocultural evolution, as the body is included in the interpenetration between human beings and social systems. From the theory of social systems, which finds its definitive formulation in Die Gesellschaft der Gesellschaft (1997), it is understood that societal structure conditions and gives the possibility of the construction of selfdescriptions in society, about the society itself, which condense into a semantic. On the contrary, it is not admissible that semantics transform societal structures. So, now the reader can wonder what the body really is: A societal structure? Or a mere semantic construction of society? The first definition given at the beginning of this work, according to which the body is understood as a conglomerate of organic systems, is 


\section{Calise, S. G. - Luhmann's Conception of the Body}

theoretically ambiguous enough, as to generate big problems. Firstly, it affirms that the body is not a system and, especially, not an organic one. As it is known, the Luhmann's operative constructivism begins with the statement that there are systems, and these perform operations that have a temporally limited duration. The operativity of the systems would be a sort of "empiric basis" of the theory. Then, if the body is not a system, it would not have its own operativity, so it would not develop structures. But, if the body is not a system, would it be a semantic construction of society? The mere fact of distinguishing the human body from the rest of the organic world is also an achievement of the self-descriptive evolution of society, in the same way as it was for the case of the psychic system's individualization and independization with respect to the body. Although, this would not indicate that the psychic system is a mere semantic formula, without operative ground. In the same way, it is conceivable that the body isn't either.

The other mentioned alternative makes reference to the possibility of considering the body as structure. For Luhmann's systems theory, the concept of structure makes no allusion, necessarily, to something material, to some sort of framework or skeleton that maintains the system united. Otherwise, the function of structure, in a system as complex as society, is to make feasible the autopoietic reproduction from event to event, restricting the field of possibilities of connection from element to element. In the context of social systems, as all its elements (or operations) are events, this means that structures are temporalized, so they assume the form of expectations. Owing to the fact that structures exist only as present in each moment and as they make reference to something expectable, they are resistant to time. Regrettably, Luhmann does not go forward in the analysis of another sort of structure apart from the social structures, as it would be difficult to understand that the body would be a structure, at least in these terms. If one understands that the body is a structure, it would be necessary to determine the selectivity of which type of system it limits (that of the organic, the social or the psychic systems). Regarding the organism, it should be considered, whether it is each organ, inserted in a specific system, or if it is the whole body, which limits the selectivity. Anyway, this discussion does not substantially concern sociology, given that if the body was a structure only useful for organic systems, it would have no sociological relevance. If, as much psychic systems as social systems, the body presents itself as a set of movement capacities, it would be more 


\section{Calise, S. G. - Luhmann's Conception of the Body}

correct to think about it as a medium, namely, as a set of loosely coupled elements. In this way, the body can work as the most primitive communication medium, through gesture. But, at the same time, socialization would limit or expand this movement potential, reducing or increasing the number of available combinations. A clear example of this is provided by MAUSS' (1936) study on the body, where the French anthropologist indicates that in many western countries people have lost the capability to crouch, something that kids in those countries or adults in other latitudes can do. In this sense, the permanent interpenetration situation, in which the body takes part, may amplify or reduce the movement range of the joints, the extension of the muscles, as well as conditioning the posture and the bodily hexis in general. Nevertheless, to characterize the body as a medium would be not enough, since the psychic system can also be interpreted as medium for society (1995e).

Another alternative to conceptualize the body can be found if one understands it as the internal environment of the organic systems. This concept of internal environment is utilized in the theory of society to characterize the "public", conceived as the internal environment of all the sub-systems of society $(1988 ; 2000 ; 2009)$, which emerges from the differentiation of the system with respect to its environment. This process also implies the reproduction of the difference between system and environment inside the system. In this way an internal environment emerges to the system itself, which is domesticated and specified, thanks to the existence of external limits to the general system (1988). Examples of this for the sub-systems of society are the market for economy (1988) and the public opinion for politics (2000). Even if the aforementioned conglomerate of organic systems does not constitute an allencompassing system, it can be thought that the body constitutes this internal environment to all these systems, which is constituted by the participation of all of them, but which is not identified with either of them. Going a bit afar, this formulation can be completed with the idea that the different organic systems, through diverse performances (Leistungen) would help the autopoietic reproduction of the body in its entirety, as a result of the accomplishment of their functions.

From all this it can be concluded that the body does not constitute a structure, even though it can be thought as a medium for social and psychic systems. This means that there is no risk to contradict one of the fundamental postulates of the theory, that is, that semantics can never determine the structure. Referring to the usage of the body, in 


\section{Calise, S. G. - Luhmann's Conception of the Body}

principle, it must be accepted that the body becomes socially relevant only if it communicates or helps to communicate something. Then, the communicatively relevant corporeality is tied, through interpenetration, to the communicative operation being carried out. This also includes the situations in which it is thinkable that somebody, due to his/her dress style, his/her postures or gesture, is indicating something, even if he/she has no intention to do that ${ }^{7}$. While a psychic or a social system can distinguish between utterance and information, there will be communication. If these considerations are right, it would be difficult for the very systems theory to accept that semantics can influence the fulfillment of the communicative operation. This is due to the fact that, if one really admits that socialization is always self-socialization, namely, that there is no transmission of information, semantics has no way to affect the decisions of a system on the ways that it has to behave with respect to its body.

Notwithstanding this, the doubt around the problem of the relationship between semantics and structure is amplified, when LUHMANN in Love as Passion (1982) suggests that the semantic tradition of amour passion and romantic love have favored the differentiation of the system of the intimate relations. The author protects himself saying that a retrospective survey would be necessary to observe to what extent this was possible.

To finish with the semantic problems, probably the most perturbing interpretation is to consider the body as only an observational unit. This vision can be grounded on the definition of the body as a conglomerate of organic systems. In this sense, the unity of the body is only given by the observer, who attributes limits, which do not correspond to the limits of a system. For consciousness, the body is that unit that allows itself to differentiate itself from the environment and also to locate others in the world. With the bodily experience, consciousness can identify what belongs to it and what does not (1995d), and consciousness develops from the first moment identifying it with the body (1995a). Nevertheless, adds Luhmann, the identification with the body fails, because the body is only given as a form, namely as a difference (in a spencerbrownian sense). But this does not prevent thinking that the body would be a semantic

\footnotetext{
7 This communicative potential of the body is related to one of the foundations of Le Breton's (1992) sociology of the body, which states that the body, as much emitter as receiver, produces meaning constantly. Anyway, the place given to the body as a potential communication medium in Luhmann's theory is minimal, as he privileges the analysis of speech, writing, print, and the generalized symbolic media of communication. In this sense, this theory can only provide quite rudimentary tools to a sociology centered on the body analysis, even when it works as a communication medium.
} 


\section{Calise, S. G. - Luhmann's Conception of the Body}

product, a construction of an observer. In a certain way, this understanding can have some relationship with the lacanian conception of the body. According to SOLER (1984) one is not born with a body, but one constructs it. To do so, in a first lacanian interpretation, one needs a living organism and an image. In this way one needs to attribute to the unity of the image the feeling of the unity of the body. This unity is given by a visual Gestalt and it is seized by the subject from the unity of his form in the mirror. In a subsequent period, Lacan interprets that as the signifier, which introduces the discourse in the organism. This means also that, as subjects of the signifier, we are separated from the body. Without going into the details, which can mark deep differences between the two theories, the main coincidence is, first, the difference between the organism, which is given, and the body, which is constructed through a "linguistic" activity, let us say. In addition, the psyche perceives the distance between it and the body. On the other hand, for both authors this does not mean that the body is a mere illusion, a phantasm. As was previously shown, Luhmann still talks about a lived body and feelings associated to it.

\section{Symbiotic mechanisms}

Once communication becomes a process (1995c), it faces three improbabilities: that ego understands what alter expects (solved through language); that communication arrives to more people than those present (solved through the media of dissemination: writing, printing and electronic broadcasting); that ego accepts and takes into account alter's communication. This last situation is solved thanks to the generalized symbolic media of communication (GSMC), which transforms the probability of a "no" into a "yes", producing a highly improbable combination of selection and motivation. Their function is to ensure that ego's expectations will turn into premises for alter's selections. They are truth, love, power/law and property/money ${ }^{8}$ (1997). To each of them corresponds a symbiotic mechanism: perception for truth; sexuality for love; physical violence for power (within the limits of law); necessities for property and money.

These symbiotic symbols or mechanisms order the way in which communication lets itself be irritated by the body, namely, the way in which the effects of the structural

\footnotetext{
${ }^{8}$ Previously (1995b), LUHMANN had also included (in a rudimentary form) religious belief, art and basic values, although it seems that he was not convinced with that decision.
} 


\section{Calise, S. G. - Luhmann's Conception of the Body}

coupling are processed in a communication system without breaking the system's closure and without the need to resort to a non-communicative operation (1997). In this way, the function of these social devices is to make possible the activation and steering of certain organic resources, at the same time that it gives them a socially manageable form to the organic irritations (1981). It must be stressed that in the article "Symbiotische Mechanismen" (1981), which appeared in 1974, the word "body" is never utilized. It only talks about the organic. This changes clearly with Social Systems, from 1984, and Die Gesellschaft der Gesellschaft, from 1997. In these texts the symbiotic mechanisms or symbols are tied to the corporeality and not to the organism. It is not clear how this slight but very significant change must be interpreted.

On another side, it must be underlined that the differentiation of the GSMC also entails the parallel differentiation of the symbiotic mechanisms, so that the reference to the corporeal becomes highly specific and is limited to the important aspects. In this sense, the symbiotic mechanisms could function, until a certain point, without the necessity of the corresponding corporeal process, as there is also the case of corporeal events that show no social importance; consequently they are ignored. As a result, the interpenetration between human being and social system, which entailed a highly abstract coupling, becomes more concrete with this concept. Nevertheless, it must not be forgotten that this is only a punctual case under which the interpenetrative bond is presented, with which the generality continues to be necessary for the description of the other communications, which do not use GSMC.

Delving into the problem of interpenetration between human beings and social systems under the application of GSMC, Luhmann states that organic processes are conditioned by these mechanisms, without arriving to determine the factual existence of these processes. This conditioning, which in the language of systems theory can sound dangerous, simply means that: physical violence must be applied according to the code of power, only under circumstances defined by law; perception provides truth, under the high requirements of the reigning science, only when it answers to a theoretically relevant question; in a highly developed economy, the satisfaction of the needs, under the assumption of scarce resources, is only possible, if one can pay for the desired products; the interminglement in a sexual relationship is conditioned by previous communications, testified by love (1981). 


\section{Emotions}

Emotions can be another place, where one can look for a corporeal reference in this theory, but, at least in Luhmann's version, it is not so. Regarding the luhmannian conception of emotions, the only explicit appearance of this concept is in the seventh chapter of Social Systems (1995c), where it is explained that the expectations of the psychic systems can condense into claims. The latter must be counterbalanced. In a stratified society this happens through the possibility to deduce pretensions from the merits tied to the social stratus. In contrast, in a functional differentiated society money is the one responsible for the transference of merits to claims. On the other hand, claims put into play the distinction between fulfillment and disappointment in a way that emotions would work as processes of internal adaptation. As psychic systems can launch their claims without much ground, this exposes them to their own emotions if claims do not become routine. As a consequence, modern society would be exposed to the risk of emotionality, in a diametrically opposed way to the weberian fear of the extinction of emotions under the realm of rationality. As individuals cannot ground their expectations in merits, but just only in themselves, these are compelled to produce selfdescriptions, as a result:

[...] the individual is forced to produce reflections and self-presentations (which can never be 'accurate'). One encounters difficulties in doing this, looks for assistance, and develops the additional claim to a comprehensible, if not therapeutic, treatment of one's claims. This last claim to assistance in grounding claims is so absurd that it is as easy to accept as to reject (1995c: 270).

As it can be observed, emotions would be an emergent element opposite to situations of disappointment of claims, so they are not psychic components that intervene constantly in the autopoiesis of consciousness. On the other hand, Luhmann seems to dismiss that disappointment of expectations, which do not condense into claims, could generate emotions, which is not very believable. In the journal Soziale Systeme's first issue of 2004, a discussion on this problematic point of the Luhmann's systems theory is proposed, beginning with Luc CIOMPI's (2004) criticism. This author indicates that the problem of emotions constitutes a blind spot for Luhmann's theory.

From the 80's, CIOMPI (1988) was working in the relationship between affect and cognition from a systems theory, trying to conciliate the developments of Piaget and Freud in those fields. In that study it was emphasized that affectivity as much as 


\section{Calise, S. G. - Luhmann's Conception of the Body}

cognition matures in phases that only partially overlap, consequently the progress in an area provides the bases for the development in another. Affectivity will acquire the form of energy, while cognition that of structure. On another side, affectivity represents the basic means of communication between living creatures, at the same time that cognitive functions remain in the background for a long time. This brings the Swiss psychologist to conceive of the psyche as a sort of double system, built by two components: the emotional one will be anchored in material, physical and concrete phenomena, which are directly tied to perception and action; while the intellectual and cognitive component differentiates the structures grounded on the biological and sensoriomotor realm. When both components are in harmony, they strengthen and validate each other, but when there is disharmony, both refute and enfeeble themselves, generating an uncomfortable tension, a state of uncertainty and anxiety, so that there is a disagreement in the totality of the body-mind system. Here Ciompi intends that emotions imply a "dialog" between body and psyche, so they are not merely psychic episodes. In Luhmann's theory, this could have been interpreted with the concept of structural coupling and irritation, as seen in the case of the symbiotic mechanisms. In spite of this, Luhmann seems to ignore that the body could trigger any emotion, considering them only as a result of the disappointment of claims. As a consequence, this concept of emotion lacks any bodily anchorage.

On the other hand, STENNER (2004) plays down the critical vision of Ciompi with respect to Luhmann's ideas, indicating that the last author's theory is not completely alexithymic, but it is based on a cognitivist vision of the problem. Stenner's interpretation differs from Ciompi's one, as he understands emotions as "threshold phenomena", since they exist neither completely inside, nor outside social, psychic and organic systems. The author adds that emotions form a "parasitical coupling" between organism and psyche, so they will manifest themselves organically as affects, while these affects will take the form of different subjective forms in consciousness (emotions). In this way, affects will generate consciousness, by means of the stimulation of different organic regions, but emotions will also "become directly amenable to conscious control, cultivation, manipulation and socialization" (CIOMPI 2004: 172). As a result, consciousness will be composed of a combination of affects into more complex compounds with new emergent dynamics. In spite of this, emotions will also be part of social systems, so they would play a communicative role that increasingly frees from 


\section{Calise, S. G. - Luhmann's Conception of the Body}

organic and conscious limits, which continuously provide proto-communicative potential. Stenner's proposal, in a certain sense, comes to compensate the lack in Luhmann's theory remarked in the previous paragraph, with his interpretations of emotions as threshold phenomena. What must be stressed from Stenner's position is that he eliminates any reference to the body, and substitutes it with the organism. As it has been seen, they are not synonyms. On another side, treating the body as a medium can also be seen as considering it a threshold phenomenon. The problem with the threshold in this theory is always the operative reference. To solve this problem, following Stenner, affects must be considered as a sort of performance (if not an operation) of the organic system, and emotions as an operation of consciousness or as a process which implies attention processing — so as to incorporate them into the operativity of the consciousness. In this way, the "threshold" characteristic of emotions is solved into the operativity of these two systems. What remains unanswered is the place of the body itself in this debate.

More recently, RIESE (2011) has outlined her dissent with the aforesaid, indicating that emotions do not need to be consciously perceived, nor do they need to be the other side of organic affects. This means that they can be psychic phenomena without external trigger, or psychic reports provoked by perturbations coming from society. In this sense, as psychic systems depend on social systems for their own autopoiesis, the first ones develop emotional reactions referred to the perceived level of viability of the second ones. This means that emotions indicate whether the structures of the social systems are viable or not for the prosecution of the psychic and organic autopoiesis. On another side, the function of the emotions with respect to organic systems is to ensure the autopoiesis of these ones, coupling themselves to psychic systems and inducing them to act in a way that can help the organism. Finally, Riese understands that psychic systems can experiment positive emotions when their expectations are fulfilled or they act in accordance with some values, while negative emotions signal the violation or omission of those values. Consequently, emotions could be the symbiotic mechanism of values, which, in some of Luhmann's writings, are conceived as a generalized symbolic medium of communication. With this proposal, Riese extends Stenner's analysis, emphasizing the psychic side of the phenomenon, completely obliterating the reference to the body. Only a little reference to the organism remains, when she states that emotions ensure its autopoiesis. But what these 


\section{Calise, S. G. - Luhmann's Conception of the Body}

theorizations systematically ignore is, following Ciompi, the fact that emotions are not isolated episodes in psychic life, but constant ones.

These reflections show the complexity of the problem of emotions and the difficulty of its seizure. Even simplifying the arguments to the extreme, it is difficult to take only one decision and place emotions in only one domain, whether it was the psychic, the bodily or the social. Nevertheless, what seems more convincing is the impossibility to think about emotions, feelings and/or affects as mere isolated episodes that work as alarms in case of disappointment, as Luhmann expects to do. Much more persuasive is Ciompi's point of view, since he interprets the affective component as constantly operating next to the cognitive one, despite the fact that it can go unnoticed (or ignored). In any case, these considerations do not provide any robust reflection on the body and, sometimes, as in Stenner's and Riese's case, only its organic aspect is contemplated.

\section{Discussion: Body - Psyche Dualism}

As a conclusion, it is possible to return to the initial point, so as to reconsider the concept of body, which is expounded here. As has remained clear, Luhmann proposes a dualist, or better, a threefold schema, since he understands that there are three types of systems differentiated by their operative modes. These three systems are in a constant relationship of interpenetration. With respect to the Cartesian conception, the differences that distance systems theory from it have been remarked, although the similarity with reference to the dualism psychic-body system persists. In spite of the fact that Luhmann renounces explicitly any research that tries to find the essence of these two systems, the concepts of emergence and meaning mark a clear distinction between the organic and the psychic, preventing any reductionism, which would attempt to explain the psychic through the brain operations, or behavior through the genetic trait of a human being. The difference between these diverse "reality orders" guarantees the exclusion of any reductionism, but, for some, it installs completely artificial compartmentalizations. In this sense, BUNGE (2010), against every dualism, stands for a materialist monism; therefore, that which philosophy has called "mind" would be reducible to brain operations. Some of the reasons that the author gives to abandon dualism are that: this is irrefutable, as it is impossible to manipulate something non- 


\section{Calise, S. G. - Luhmann's Conception of the Body}

material; it is inconsistent with cognitive etiology, which demonstrates that the human being shares some mental abilities with other animals; it violates the laws of physics, since it goes against the principle of conservation of energy, etc. Paradoxically, a conception like this is the first to reproduce the Cartesian simplifications with respect to the body, considering it as a machine, now steered by the brain, which is the one which thinks, feels, perceives, etc. In Bunge's conception, materiality would be ensured by the facticity of organic processes of the diverse bodily organs, as this was something given in itself. As well remembers BUTLER, from a foucauldian perspective, the body materiality is given by "a process of materialization that stabilizes over time to produce the effect of boundary, fixity, and surface" (BUTLER 1993: 9). But this process must always be thought of as an effect of a power that is regularly exercised. From this perspective, FOUCAULT (1994) affirms that bodies do not exist as mere biological or material items, but they exist within and through a political system, while LE BRETON (1992) will say that these do not exist in a natural state, but only inserted in the weave of meaning. From a very different viewpoint, systems theory also renounces to every apriorism, which expects to establish some "in itself" prior to any social experience capable of describing it. The concept of co-evolution implied in the interpenetration relationship indicates that neither the corporeal, nor the psychic, nor the social are thinkable and they cannot exist in isolation.

Returning to Foucault, it seems that the French philosopher proposes no clear monist conception, but neither a dualist one. Maybe a bit ironically, FoUCAULT (1975) talks about the difference between body and soul, interpreting the last one as the result of punitive, of surveillance and coercion procedures, namely, an element where the effects of a certain type of power and a reference to a knowledge are articulated. As a result, soul would not be more than a piece in the domain that power exercises over the body. This strong stress on the domination of power over the bodies (and souls), would make one think of a unidirectional relationship, incompatible with the idea of coevolution. On the other hand, there are two more problems strictly related to the aforementioned. The first one makes reference to the form that assumes the relation, since, in principle, for Foucault, the fundamental relationship is that between body and power, which generates the emergence of the soul, which would be a way of interiorizing the power itself. This makes thinking that the psychic raises only as an effect of power, which is social, on a body, therefore power would be temporally 


\section{Calise, S. G. - Luhmann's Conception of the Body}

previous. Moreover, renouncing to an ontological way of understanding the soul (as also the body), in addition to the irony of talking about a soul, it is not clear if the author would be playing with the reader, so to destabilize his ontological surenesses, or if he really means the aforesaid. With respect to this point, systems theory is soberer and, also giving up ontology, states the existence of psychic systems, as these perform operations. This means that the psychic cannot be understood as a mere illusion, but neither as a pure social product. Additionally, Luhmann rejects an all encompassing conception of power - even though he interprets it from a relational point of view-, so as to understand it as a GSMC. In this sense, while Foucault emphasizes the importance of the body, Luhmann prioritizes the analysis of the psychic, largely ignoring and giving no clear place to the body, sometimes confused with the organic systems.

A more concrete critique against any dualism is presented by ELIAS (1991; 1994), considering that the difference between individual and society is purely artificial, since these would be two sides of the same phenomenon, that is the human being. This differentiation would be a historical product, which, in the West, becomes archetypical with the emergence of the homo clausus conception, in which he would be isolated from the external world and from the other human beings, by invisible walls. This would be the unquestioned fundament of many philosophical and sociological theories. Nevertheless, for Elias, this division would not be possible without a firmer, more universal and more regular contention of affects. In this way, developing the concepts on an empirical basis, it would be evident that both are processes and not isolated essences. If one accepts this conception, it would be necessary to finish with disciplinary differentiation, founded on a simple ghost, which ends by distorting the real meaning of things. As a result, it would not be very fruitful to continue wondering abstractly, as in this work, on the relationship between body, psyche and society, as this is solved simply in empirical research. Naturally, this quite naive hint with respect to the solutions that empirical research would contribute seems to be, at least, arguable.

\section{Bibliographic references:}

BourdieU, Pierre. Le sens pratique. Paris: Les Éditions de Minuit 1980.

Bunge, Mario. Matter and Mind. A Philosophical Enquiry. New York: Springer 2010.

BUTLER, Judith. Bodies that Matter. On the Discursive Limits of "Sex". New York and London: Routledge 1993. 
Calise, S. G. - Luhmann's Conception of the Body

CiOMPI, Luc. The Psyche and Schizophrenia. The Bond between Affect and Logic. Cambridge and London: Harvard University Press 1988.

. Ein blinder Fleck bei Niklas Luhmann? Soziale Wirkungen von Emotionen aus Sicht der fraktalen Affektlogik. In: Soziale Systeme 10(1), 2004, 21-49.

ELIAS, Norbert. The Society of Individuals. Oxford: Blackwell 1991.

. The Civilizing Process. Sociogenetic and Psychogenetic Investigations. Oxford: Blackwell 1994.

FOUCAULT, Michel. Surveiller et punir. Naissance de la prison. Paris: Gallimard 1975.

. Histoire de la sexualité I. La volonté de savoir. Paris: Gallimard 1976.

. Dialogue sur le pouvoir. In : Dits et écrits III. Paris: Gallimard 1994, 470-475.

HAHN, Alois / JACOB, Rüdiger. Der Körper als soziales Bedeutungssystem. In: FuCHS, Peter / GöBEL, Andreas (eds.). Der Mensch - das Medium der Gesellschaft. Frankfurt a.M.: Suhrkamp 1993, 146-188.

LE BRETON, David. La sociologie du corps. Paris: P.U.F., 1992.

LuHMANN, Niklas. Symbiotische Mechanismen. In: Soziologische Aufklärung Bd. 3. Soziales System, Gesellschaft, Organisation. Opladen: Westdeutscher Verlag 1981, 228-244.

. Liebe als Passion. Zur Codierung von Intimität. Frankfurt a.M.:, Suhrkamp 1982.

. Soziale Systeme. Grundriss einer allgemeinen Theorie. Frankfurt a.M.:, Suhrkamp 1984. . Die Wirtschaft der Gesellschaft. Frankfurt a.M., Suhrkamp Verlag, 1988.

. Die Form ,Person‘. In: Soziologische Aufklärung 6. Die Soziologie und der Mensch. Opladen: Westdeutscher Verlag 1995a, 142-154.

. Die operative Geschlossenheit psychischer und sozialer Systeme. In: Soziologische Aufklärung Bd. 6. Die Soziologie und der Mensch. Opladen: Westdeutscher Verlag 1995b, 26-37.

. Social Systems. Stanford: Stanford University Press 1995c.

. Wahrnehmung und Kommunikation sexueller Interessen. In: Soziologische Aufklärung Bd. 6. Die Soziologie und der Mensch. Opladen: Westdeutscher Verlag 1995d, 180193.

. Wie ist Bewusstsein an Kommunikation beteiligt? In: Soziologische Aufklärung Bd. 6. Die Soziologie und der Mensch. Opladen: Westdeutscher Verlag 1995e, 38-54.

. Die Gesellschaft der Gesellschaft. 2 Bd. Frankfurt a.M.: Suhrkamp 1997.

. Die Politik der Gesellschaft. Frankfurt a.M.: Suhrkamp 2000.

. Einführung in die Systemtheorie. Heidelberg: Carl-Auer-Systeme Verlag 2004.

. Die Realität der Massenmedien. Opladen: VS Verlag 2009.

MAUSS, Marcel. Les techniques du corps. In: Journal de Psychologie XXXII(3-4), 1936, 271 293.

MERLEAU-PONTY, Maurice. Le visible et l'invisible. Paris: Gallimard 1993.

. La phénoménologie de la perception. Paris: Gallimard 2001.

RIESE, Juliane. Functions, Communication, and Perception of Emotions in Luhmannian Theory: Emotions as Reflection Resources of Social Systems. Soziale Systeme 17(1), 2011, 5372.

RYLE, Gilbert. The concept of mind. $60^{\text {th }}$ Anniversary Edition. New York: Routledge 2009.

SOLER, Colette. Le corps dans l'enseignement de Lacan. Quarto Revue de la Cause Freudienne en Belgique 16, 1984, 44.

STENNER, Paul. Is Autopoietic Systems Theory Alexithymic? Luhmann and the SocioPsychology of Emotions. In: Soziale Systeme 10(1), 2004, 159-185. 
Calise, S. G. - Luhmann's Conception of the Body

TURNER, Bryan. Recent Developments in the Theory of the Body. In: FeATHERSTONE, Mike / HePworth, Mike / Turner, Bryan. (eds.). The Body: Social Process and Cultural Theory. London: Sage 1991.

VON FOERSTER, Heinz. Molecular Ethology, an Immodest Proposal for Semantic Clarification. In: Understanding Understanding: Essays on Cybernetics and Cognition. New York: Springer 2003, 133-167.

Recebido em 04/09/2014

Aceito em 21/11/2014 